\title{
An Intensive Short Course on Atomic-Force Microscopy
}

\author{
Nancy A. Burnham*, Andrea Arcifa", Mohammad Divandari", Christian Mathis", \\ Shivaprakash N. Ramakrishna", and Nicholas D. Spencer"
}

* Depts. of Physics and Biomedical Engineering, Worcester Polytechnic Institute, Worcester MA 01609, USA

" Laboratory for Surface Science and Technology, Dept. of Materials, ETH Zürich, 8093 Zürich, Switzerland

\begin{abstract}
A course on atomic-force microscopy (AFM) that has been previously taught to undergraduates and graduate students over a semester or a half-semester was taught in short-course format. The course structures are compared, the resources for the short course are described, the short course is evaluated, and recommendations are given.
\end{abstract}

Keywords: atomic-force microscopy, nano-education, laboratory experiments in physics education PACS: 68.37.Ps, 01.50.Pa

\section{INTRODUCTION}

Atomic-force microscopy (AFM) is a technique that allows the imaging of topography and materials' properties at the micrometer and nanometer scales. Its operational principle-a sharp tip on a flexible beam that is rastered over a sample surface-is very easy for students to understand. Hence it offers a path for students to become familiar with the interdisciplinary and dynamic field of nanoscience.

AFM has been taught by the first author at Worcester Polytechnic Institute (WPI) since 2001 on a semester (graduate students) or half-semester (undergraduates) basis. The courses attract students with a range of backgrounds and levels, almost half of whom go on to use AFM. The materials for and outcomes of the courses are described in Reference 1. To the authors' knowledge, no educational literature exists concerning AFM short courses.
In the summer of 2015, AFM was taught in an intensive, short-course format at ETH Zürich using WPI's course materials, in order to advance the research of graduate students within the Department of Materials. In this manuscript, we describe the differences between the course structures, the resources that were used, the course's level of success, and what will be changed in the future. Although this pilot course was taught to graduate students, the lessons learned can be equally well applied to an intensive course for undergraduates, perhaps at the beginning of a summer research program.

\section{COURSE STRUCTURE}

The core aspects of the WPI course are the three different types of laboratories, represented by the photographs in Fig. 1: a) instrument labs, b) computer

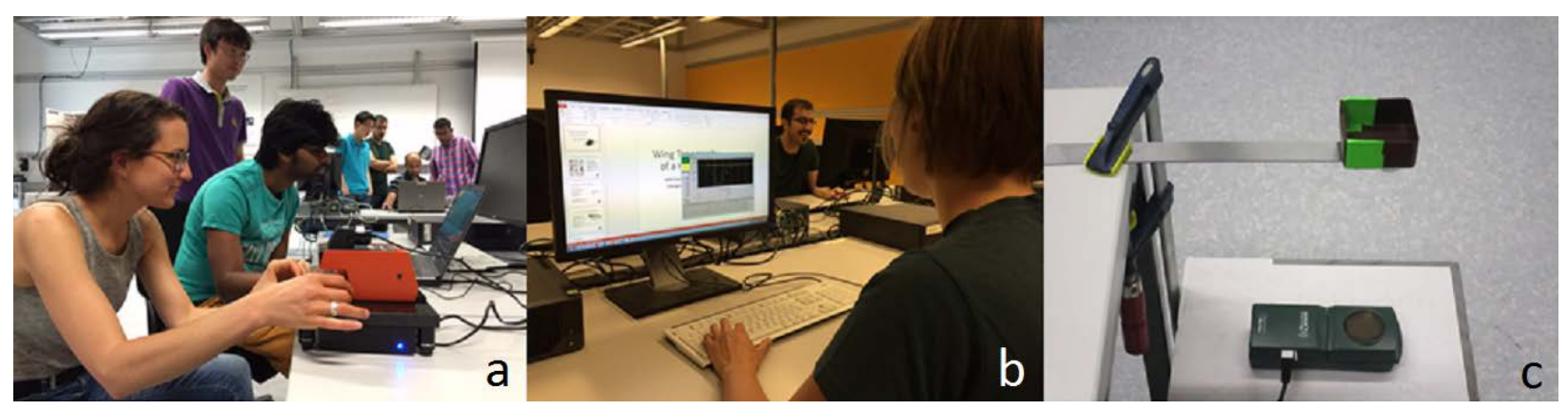

FIGURE 1. Photographs representing the three different types of laboratories: a) instrument labs with the AFMs (orange device in the foreground); b) computer labs for addressing the more difficult concepts; c) "macro" labs with a macroscopic cantilever, so that students can better understand how an AFM cantilever behaves. The macro-lever has a small brown bucket with green tape on top for placement of weights. Below the lever is a motion sensor, interfaced to a computer for data collection.

\footnotetext{
2015 BFY Proceedings, edited by Eblen-Zayas, Behringer, and Kozminski; Peer-reviewed, doi:10.1119/bfy.2015.pr.006 Published by the American Association of Physics Teachers under a Creative Commons Attribution 3.0 license. Further distribution must maintain attribution to the article's authors, title, proceedings citation, and DOI.
} 
TABLE 1. The topics covered in the three types of laboratories. They are described in detail in Reference 1.

\begin{tabular}{l|l|l|l}
\hline Day & Instrument Lab & Computer Lab & Macro-Lab \\
\hline $\mathbf{1}$ & Laboratory procedures, basic imaging & Image processing & Static spring constant \\
\hline $\mathbf{2}$ & Practical quiz, scan and display options & Feedback and noise & Tip imaging \\
\hline $\mathbf{3}$ & Optimizing an image & FFTs and fourier filtering & Dynamic spring constant \\
\hline $\mathbf{4}$ & Scanner and probe calibration & Potentials, forces, and stiffnesses & Cantilever instabilities \\
\hline $\mathbf{5}$ & Force-curve acquisition, dynamic mode & Surface forces and stiffness & Force curve, stiff sample \\
\hline $\mathbf{6}$ & Capstone inquiry session & Contact mechanics & Force curve on unknown \\
\hline
\end{tabular}

labs, and c) labs with a macroscopically sized cantilever. These were the activities around which the ETH course was organized. As there are at least six of each type of laboratory (listed in Table 1), the ETH course was chosen to be seven full working days in length, with evening homework. Students earned three credits by passing the course, which was graded on a pass or fail basis. The daily course schedule is presented in Table 2. Two two-hour lab sessions were placed in the morning and afternoon, bracketed by discussion sessions at the beginning and end of the work day. Students were expected to preview the next day's material in the evenings and contribute to an online discussion at the course website. (The course content was digitized and posted at YouTube.com/ AtomicForceMicro in 2013 and has since received over 350 subscribers and 50,000 hits.)

Other expectations of the students were to prepare for a morning quiz on the upcoming instrument lab, to submit a daily summary of their activities, and to choose a sample to study. This latter "mini-project" was carried out in a team-the same team with which

TABLE 2. The typical daily schedule for the intensive AFM course, which compressed a semester of material into seven days. Two two-hour lab periods were bracketed by morning and afternoon discussion sessions. In the evenings, the students were expected to preview the next day's material.

\begin{tabular}{l|l}
\hline Time & Activity \\
\hline 09:00-10:00 & $\begin{array}{l}\text { Morning quiz, orientation to day’s } \\
\text { activities, Q\&A }\end{array}$ \\
\hline 10:15-12:15 & $\begin{array}{l}\text { Instrument lab or computer and } \\
\text { macro-lab }\end{array}$ \\
\hline 12:15-13:15 & Lunch \\
\hline $13: 15-15: 15$ & $\begin{array}{l}\text { Computer and macro-lab or } \\
\text { instrument lab }\end{array}$ \\
\hline $15: 15-16: 00$ & $\begin{array}{l}\text { Study period for daily summaries, } \\
\text { finishing labs, coffee break, etc. }\end{array}$ \\
\hline $16: 00-17: 00$ & $\begin{array}{l}\text { Feedback on previous day’s daily } \\
\text { summaries, pair-and-share } \\
\text { debriefing, submission of daily } \\
\text { summaries, Q\&A }\end{array}$ \\
\hline Evening & $\begin{array}{l}\text { Video lessons, contributions to } \\
\text { online discussions }\end{array}$ \\
\hline
\end{tabular}

they would do their laboratory exercises. On the last day of the course, the teams presented their work in a short talk, as well as submitted text and video abstracts.

Given the tight time constraint of the ETH short course, several aspects of WPI's semester and halfsemester courses were dropped. The similarities and differences between the courses are detailed in Table 3 . At WPI, the courses run over seven or fourteen weeks. More class time means that quantitative homework problems can be solved during class. Exams are then based on the homework problems. There is also adequate time between laboratories such that the students are asked to write formal lab reports. Extensive feedback is given in the form of a grading rubric for the lab reports and in-class writing exercises. At ETH, assimilation of the material was accomplished via daily summaries and pair-and-share debriefings at the end of the day.

TABLE 3. The activities associated with the half- or fullsemester ("term") courses as compared to the intensive course. Although many aspects are shared, there is much less emphasis on writing in the intensive course. The daily summaries and pair-and-share debriefings in the intensive course provide alternative means for the students to assimilate the day's activities.

\begin{tabular}{l|l|l}
\hline Activity & $\begin{array}{l}\text { Term } \\
\text { course }\end{array}$ & $\begin{array}{l}\text { Intensive } \\
\text { course }\end{array}$ \\
\hline Pre-lab quizzes & Yes & Yes \\
\hline Instrument labs & Yes & Yes \\
\hline Computer labs & Yes & Yes \\
\hline Macro labs & Yes & Yes \\
\hline Video lessons & Yes & Yes \\
\hline Online discussions & Yes & Yes \\
\hline In-class discussions & Yes & Yes \\
\hline Mini-project & Yes & Yes \\
\hline Instrument lab reports & Yes & No \\
\hline Computer lab reports & Yes & No \\
\hline In-class writing exercises & Yes & No \\
\hline In-class homework & Yes & No \\
\hline Exams & Yes & No \\
\hline Daily summaries & No & Yes \\
\hline Pair-and-share debriefings & No & Yes \\
\hline
\end{tabular}




\section{RESOURCES}

The discussions were held in a small classroom with computer projection and movable tables, set up such that all participants could easily see each other. There were twelve students, four TAs (middle authors), one instructor (first author), and the host professor (last author). The number of TAs was deliberately high for this first short-course offering, one for every three students. For future courses, one TA for every six students would be a more efficient use of resources.

The laboratories were held in one big basement computer room. All three laboratory exercises ran concurrently. The students were assigned to groups of three. The team assignments were done by the TAs, who had prior knowledge of the students' existing exposure to AFM. Each day, a different group was paired with a different TA, such that all of the students would meet all of the TAs.

The big computer room allowed the three parallel lab sessions to run smoothly. The teams were able to flow from one activity to another, and if there was a problem, it was easy to call upon a TA, the host professor, or the instructor for help.

The AFMs were Nanosurf NaioAFMs, which cost only about $\$ 20,000$ and are designed to be easy to use. Two were purchased for this course. The software for the computer labs is available from the first author. For some of the macro-labs, Vernier's Logger Pro hardware and software were used for acquisition of the motion of the macro-cantilever. The other supplies for the macro-labs are easy to assemble at a university.

\section{EVALUATION}

All of the members of the teaching staff (the authors) were pleased with their interactions with the students, with the students' many questions, and with the rapidity with which the students could begin collecting data. The reputation of AFM is that-despite the simplicity of its principles-it requires much time and effort to become a skilled operator. Contrary to its reputation, a sample AFM image that our students acquired on their first day is shown in Fig. 2.

On the last day of the course, the teams of students presented a selection of images on sample(s) of their choosing. The authors were the evaluators. All of the data were of good quality; the projects overall earned an average of $85 \%$, with a standard deviation of $3 \%$. The authors had the impression that the students learned to be competent AFM users within just seven days. Indeed, even on the second day, all teams passed the team practical quiz, during which the team must correctly follow established laboratory procedures and acquire an image (Table 1).

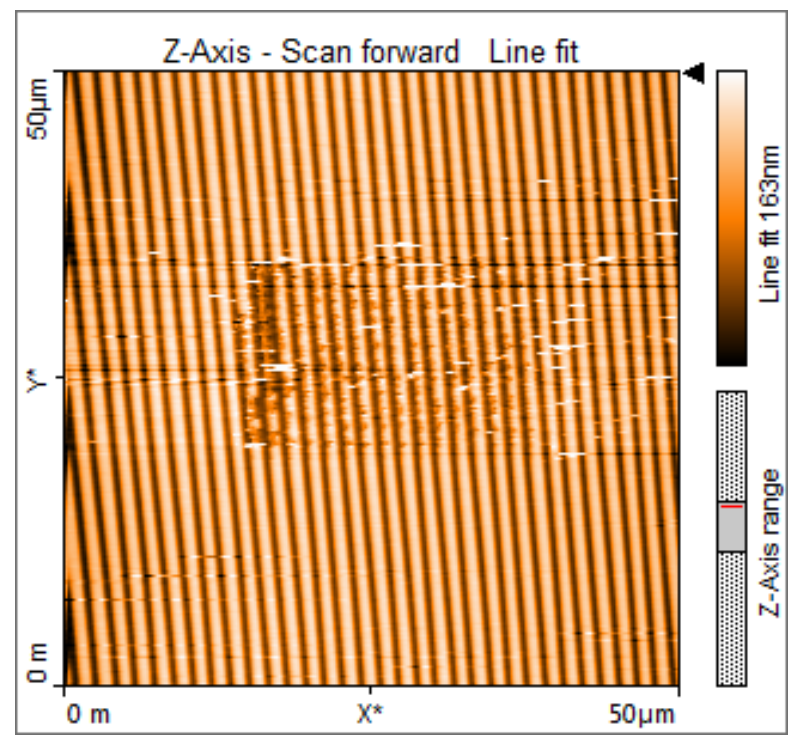

FIGURE 2. Even early in the course, the students were able to collect reasonable AFM data and learn from their mistakes. Here, the regularly spaced tracks of a CD-R are shown, with a $50 \mu \mathrm{m}$ scan range and a height scale of 163 $\mathrm{nm}$. The image was taken on the first day in contact mode, the easiest mode to understand. The students had mistakenly inserted a stiff AFM cantilever, not usually used for contact mode. Stiff cantilevers can easily cause damage because of the high pressures between the tip and the sample. After inserting the correct, more compliant cantilever, they took an image with a larger scan range to reveal the streaky, damaged area in the center, caused by the tip on the stiff cantilever. The bars to the right of the image indicate the filtering ("Line fit") and color scale, as well as the portion of the total range of the z-axis scanner that was used.

A short evaluation was also given on the last day of class; some of the quantitative results are given in Fig. 3. This in-class evaluation also included some openended questions-all students recommended stretching out the time over which the material was covered.

Furthermore, the students were asked to fill out ETH's on-line evaluation for lab courses after the course was over. The authors were pleased to see that the answers about the level of difficulty of the course were right in the middle, between too easy and too hard. (The students reported that they had had a wide range of previous experience with AFM.) They were satisfied with the equipment, the laboratory, the lab instructions, and uniformly satisfied with the mentoring. However, they were dissatisfied with the short-course format and that the learning materials were not provided in advance of the course.

Most students appreciated how far the course brought them in a short period of time. One quotation from a student is: 


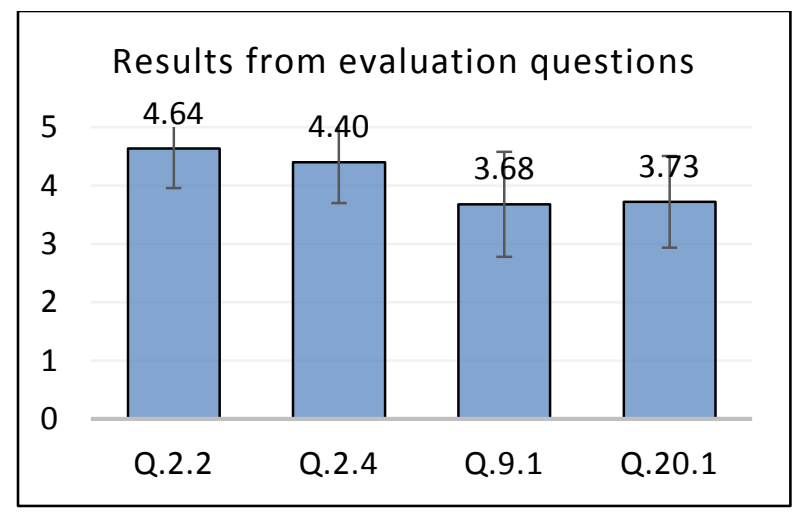

FIGURE 3. The average data from the course evaluations fell into a range from 4.64 to 3.68 on a scale of 1 to 5 , with 1 meaning Not True and 5 meaning Absolutely True. Here, the averages and standard deviations of the two highest and lowest sets of responses are shown. Question 2.2: The lecturer explained the subject understandably and clearly. Question 2.4: The lecturer motivated me to take active part in the course. Question 9.1: How satisfied were you in general with the course unit? $(1=$ Very unsatisfied to $5=$ Very satisfied) Question 20.1: The course covers a broad topic and a multitude of different aspects and methods in a coherent and stimulating form. From the free-response questions, the authors believe that most of the dissatisfaction with the course was because of its fast pace. Given that this was the first time that the material has been offered in shortcourse format, the authors were content with the students' evaluation of the course.

This is an introductory course on AFM from a practical point of view. It is good for understanding basic phenomena and acquiring knowledge on possible artifacts and their resolution.

Most students recognized how the three main laboratory components of the course were complementary: in general, the three labs addressed the same topic each day, but from different standpoints. While it was expected that the students would enjoy working with the AFMs themselves, i.e. the instrument labs, it was less obvious that students would be engaged by the computer- and macro-labs. It was very satisfying for the first author, who developed all of the lab materials, to hear in the end-of-day pair-andshare sessions how much the computer- and macrolabs were appreciated.

\section{FUTURE OFFERINGS}

The authors discussed how the course can be improved. In reaction to the students' complaints that they were overworked, the course will be expanded from seven to ten working days, such that the first day could be devoted to introductions and organization, the second to seventh day to the assigned laboratories, the eighth and ninth day to mini-projects, and the tenth day to evaluations and project presentations. The students will be notified a few weeks in advance that intensive courses require a full day of effort. They will also be told that they should start to study the online course materials in advance, in order to ease the time pressure during the course.

Specifically, the students felt time pressure by being asked to conduct mini-projects along with the assigned laboratories and to turn in their daily summaries at the end of the working day. By expanding from seven to ten days, overall time pressure will be reduced. Submission of the daily summaries will be moved to the start of the following day. Team submissions, rather than individual submissions, will be encouraged.

Some of the students (here, MS and PhD students) also noted that the materials were first developed for undergraduates. They felt that being asked to take a pre-lab quiz on the lab's activities was not appropriate for their level, which led to a perception of an emphasis on grades, rather than learning. The next time the course is given, part of the morning discussion session can be used for lab orientation, rather than prelab quizzes.

\section{SUMMARY}

The authors believe that an intensive short course on AFM can provide students with: i) a good conceptual understanding of AFM principles, ii) welldirected hands-on experience, iii) a framework with which to develop critical thinking about AFM, and iv) a solid foundation upon which to learn more. The authors plan to adapt the course and try again. In order to help other instructors begin an AFM course, be it short or long, the first author is willing to share most of the course materials.

\section{ACKNOWLEDGMENTS}

The help of Josephine Baer, Tomas Bartos, Giovanni Cossu, Sara Morgenthaler, and Marc Petitmermet, all of ETH Zürich, is gratefully acknowledged.

\section{REFERENCE}

1. N.A. Burnham, J. Nano Education 5, 109-114 (2013). 